\title{
Technological aspects of energy optimization during operating vehicles and increase their environmental safety
}

\author{
Mykola Karnaukh*, Dmitriy Muzylyov, and Natalya Shramenko \\ Kharkiv Petro Vasylenko National Technical University of Agriculture
}

\begin{abstract}
The paper discusses an actual scientific and practical problem of expanding the fuel base of the transport means by using biodiesel fuel in the form of ethyl esters made of rapeseed, sunflower and soybean oils. The choice of the optimal blend composition of diesel and biodiesel in appropriate operating conditions helps to provide the energy independence of transport companies on mineral hydrocarbons, reduce the anthropogenic influence on the environment and improve the environmental safety of transport. The research offers a new technological model for the production of biodiesel, which improves the quality and reduces the cost of biodiesel, reduces its negative impact on the elements of the vehicle fuel system. Reliability of fuel system elements is calculated. Mathematical expressions were obtained to determine the probability of failure-free operation of the fuel system and the probability of failure of its elements during operation at various fuel mixes. The assessment of the economic efficiency of the use of biodiesel as a fuel for vehicles was made.
\end{abstract}

\section{Urgency of the problem}

In anticipation of the expected shortage of mineral hydrocarbons, the development of alternative energy proceeds to a global scale. The tendency of searching for renewable resources is aimed at energetic and hence economic independence from the import of petroleum products, which is currently the primary task for our country.

An important direction in the implementation of unconventional energy resources is the environmental aspect, contributing to the reduction of anthropogenic impact on the atmosphere by reducing emissions of harmful substances.

According to the State Statistics Service of Ukraine, the main consumer of light petroleum products is the agricultural sector $(27.8 \%$ of total consumption) and transport (26.9\%) [1]. Based on these indicators, the use of alternative fuels in vehicles would help to solve the problems discussed above.

Since most of the transport work in the agriculture and transport industry is conducted by trucks, much of which are equipped with diesel engines [2], the issue of energy optimization of the operating vehicles and increasing their environmental safety when using biodiesel fuel is relevant.

\section{Analysis of publications}

Considering the relevance of the use of biodiesel as a fuel for vehicles, a lot of scientific works are focused on the study of this subject. The attention of scientists is aimed at distinguishing the physic-chemical properties of biofuels from mineral and the influence of these differences on the technical and operational characteristics of vehicles.

It has been stated that one of the main advantages of biofuel is its environmental aspect, which is manifested in the reduction of carbon dioxide emissions, products of incomplete combustion of hydrocarbons and solid particles [3]. At the same time, its use also has a negative impact, namely, it reduces the effective power of the engine with an increase in specific fuel consumption [4] and makes adjustments to the life of the parts of the fuel equipment [5]. The question arises of finding the optimal content of biodiesel in a binary mixture, which would allow to determine the total impact on the economic, environmental and operational component and to form a general positive effect.

Unfortunately, the studies of this issue has been insignificant, since they require costs of both material and time resources. In the work considering the adaptation of a diesel engine to bio-oil fuel compositions [6], the optimal biodiesel content limits are determined conditionally and range form 40 to $60 \%$. A different approach to the solution of the problem depends on the gradation of the binary mixture with a certain step of the content of esters in fuel. In this case, there is no integrated approach and the indicator is taken into account that is closest to the maximum effect either by the environmental component [7] or by engine power characteristics [8].

The analysis of the literature does not give due any proper attention to the issue of seasonal operation of biofuel transport and its impact on the fuel system resource, which depends on a number of factors,

* Corresponding author: nikolay.karnauh $@$,gmail.com 
including the kinematic viscosity of the binary mixture. Therefore, the studies in this work are relevant and of a significant demand.

\section{Research results}

The observed trend in the development of biodiesel production is based on the methyl esters of vegetable oils, determines the use of various technologies of its production, which does not always determine its perfection and affects the quality of the final product. Non-compliance with the technological process along with the absence of a powerful filtration system from mechanical impurities and purification from saponification products, glycerol and residual methanol reduces the characteristics of biofuels, which leads to disruption of engine operation and shortening the time of its operation.

The methyl alcohol used in the esterification process is produced by a few chemical plants from natural gas, its reserves are no less limited than the reserves of petroleum products [9].

In view of the foregoing, it is reasonable to replace methyl alcohol with ethyl alcohol, which is a food product and does not have a detrimental aggressive effect. The use of ethyl alcohol, produced from renewable agricultural resources, will achieve independence from petroleum-based alcohols and ensure full utilization of the production capacities of distilleries. To implement this direction, a new technology for the production of biodiesel fuel has been patented, which allows to reduce the cost and improve the quality of the final product [10].

In the process of analyzing the work on expanding the fuel base of the means of transport, the issue of changing the reliability indicators of the diesel engine fuel system elements and the fuel system as a whole during operation is also relevant. A theoretical assessment of the probability of failure of each of the elements in the fuel system, as well as an assessment of the likelihood of system failure, will justify the timing of the maintenance or repair, which will increase the efficiency of using means of transport.

Using the mathematical apparatus of the theory of operations, we obtained an expression is obtained for assessing the reliability of the diesel engine fuel system at different fuel mixes.

$$
P_{0}=\frac{1}{1+\frac{\lambda_{0.1}}{\mu_{1.0}}+\frac{\lambda_{0.2}}{\mu_{2.0}}+\frac{\lambda_{0.3}}{\mu_{3.0}}+\frac{\lambda_{0.4}}{\mu_{4.0}}+\frac{\lambda_{0.5}}{\mu_{5.0}}+\frac{\lambda_{0.6}}{\mu_{6.0}}}
$$

In the resulting formula, two parameters are used: the intensity of the failure of the fuel system's element $\lambda_{0.1}$ $\lambda_{0.6}$; recovery rate of a fuel cell element during maintenance (TO) $-\mu_{1.0}-\mu_{6.0}$.

Mathematical expressions were obtained to determine the probability of reliable operation of the fuel system during operation on ethyl ethers:

$$
P_{0 E E P O}=P_{0} \exp \left(-c_{E}\right)
$$

where $P_{0 E E P O}$ is probability of trouble-free operation of the fuel system when using mixed fuels (diesel fuel (DF) + ethyl esters of rapeseed oil (EEPO)); $P_{0}$ is probability of trouble-free operation of the fuel system on diesel fuel, the formula (1); $c_{E}$ is the share of biofuels in diesel fuel DF.

For mixed fuel $(95 \% \mathrm{DF}+5 \% \mathrm{EEPO}), c_{E}=0,05$, for $100 \% \mathrm{EEPO}, c_{E}=1$.

Dependence (2) is obtained from the simulation results and reflects the nature of changes in the reliability of the diesel fuel system when using different compositions of composite fuels, as it is shown in Fig. 1.

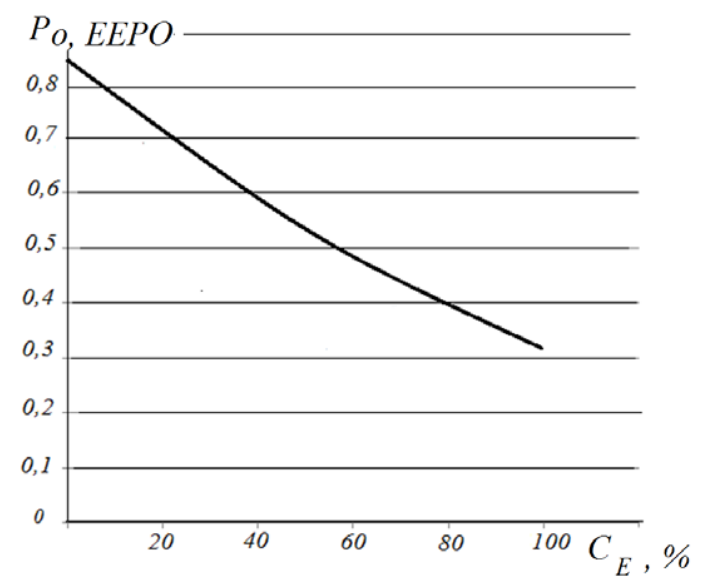

Fig. 1. Dependence of the change in the probability of troublefree operation of the diesel fuel system on the content of the volume fraction of biofuel in diesel fuel

From the analysis of the dependence presented in Fig. 1, it follows that the probability of failure-free operation also decreases exponentially with an increase in the volume fraction of biodiesel in diesel fuel.

In fig. 2. dependencies are determined that establish the degree of influence of various types of biofuel and its volume fraction in petroleum diesel fuel on the reliability indicators of the fuel system. It is shown that mixed fuels based on ethyl esters of vegetable oils lead to a decrease in the coefficient of technical use of the fuel system. When the volume fraction (30\% EEPO) in diesel fuel is exceeded, the technical utilization ratio $\mathrm{K}_{\mathrm{mв}}$ decreases to 0.72 .

Based on statistical data on fuel system failure during operation on various types of fuel (data for processing were obtained from agricultural enterprises where resource tests of vehicles on biodiesel were carried out) and mathematical modeling of the reliability of the fuel system, it has been stated that mixed fuels based on ethyl esters of vegetable oils are the most promising type of biofuel and expand the fuel base for vehicle operation.

The simulation results of the change in the probability of failure-free operation of the fuel system and the coefficient of technical use allow us to conclude that when using mixed fuels containing EEPO, it is possible to increase the volumetric content to containing methyl esters, where the concentration should not exceed $(90 \%$ DF $+10 \%$ EEPO). However, such a suggestion requires the development of recommendations for the 
maintenance of fuel systems for summer and winter periods of operation, which will increase the likelihood of trouble-free operation of the fuel system to values when operating on petroleum diesel fuel.

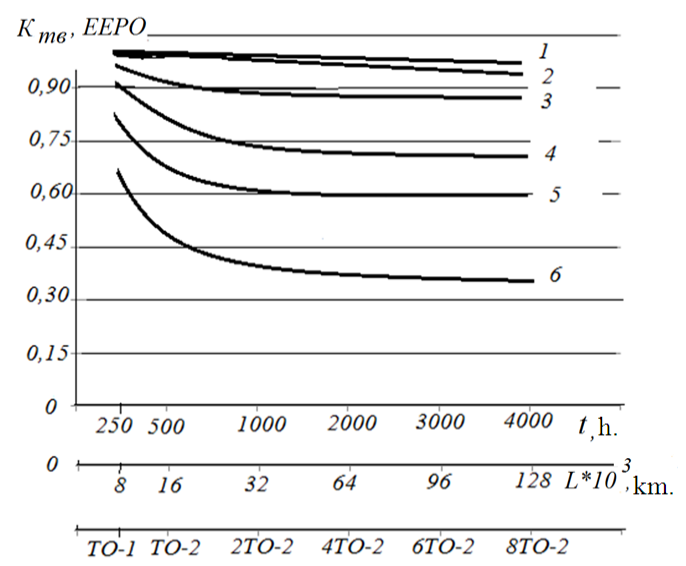

Fig. 2. Dependence on the change in the coefficient of technical use of the diesel fuel system from the use of various compositions of mixed fuels and the mileage of the truck: 1 (DF) 2 - (95\% DF + 5\% EEPO) $3-(90 \% \mathrm{DF}+10 \% \mathrm{EEPO}) 4-$ $(70 \% \mathrm{DF}+30 \% \mathrm{EEPO}) 5-(50 \% \mathrm{DF}+50 \% \mathrm{EEPO}) 6-(100 \%$ EEPO)

During bench tests of a diesel engine on various blend compositions of diesel fuel and biological in the form of ethyl esters of vegetable oils of rapeseed, sunflower and soy, dependences of the effective power $N_{e}$ and specific fuel consumption were obtained $g_{e}$. It has been found out that the use of ethyl ester of rapeseed oil reduces the effective power up to $9 \%$, ethyl ester of sunflower oil up to $11 \%$, ethyl ester of soybean oil up to $13 \%$, while simultaneously increasing the specific fuel consumption by $10 \%, 12 \%$ and $14 \%$ respectively.

Also, we experimentally obtained dependences of the reduction of harmful emissions into the atmosphere of exhaust gases when using different types of composite fuels. It has been determined that the use of ethyl ester reduces carbon dioxide emissions $C O$ by $37 \ldots 40 \%$, the emission of products of incomplete combustion of hydrocarbons $C_{n} H_{m}$ by $27 \ldots 29 \%$, the emission of solid particles (soot) $T 4$ by $16 \ldots 20 \%$ while simultaneously increasing the emission of nitrogen oxide $N O_{x}$ by $2.1 \ldots$ $2.2 \%$.

On the basis of experimental data, the following dependencies were obtained, characterizing the total emission of harmful substances into the atmosphere:

$$
E=M_{v} \exp \left(-Q_{B \%}\right)
$$

where $E$ is the total emission of harmful substances into the atmosphere, $\mathrm{g} / \mathrm{m}^{3} ; M_{v}$ is the total emission of harmful substances into the atmosphere when the engine is running on diesel mineral fuel, $\mathrm{g} / \mathrm{m}^{3}$. For the diesel engine D-243 $=0.24 ; Q_{B \%}$ is a dimensionless parameter that takes into account the reduction of harmful emissions, depending on the percentage of ethyl esters in diesel fuel.
The expression for calculating the exponent is as follows:

$$
\begin{aligned}
& Q_{B \%}=C O_{B \%} \cdot m_{C O}+C_{n} H_{m B \%} \cdot m_{C_{n} H_{m}}+ \\
& +T Y_{B \%} \cdot m_{T Y}-N O_{x_{B \%}} \cdot m_{N O_{x}}
\end{aligned}
$$

where $C \mathrm{O}_{B \%}$ is the value of the reduction in emissions at a certain percentage of ethyl esters in the mixed composition; $m_{C O}$ is the weight coefficient taking into account the "weight" (significance) in the total amount of harmful substances in the exhaust gases; $C_{n} H_{m_{B \%}}$ is the amount of emission reduction at a certain percentage of ethyl esters in the fuel; $m_{C_{n} H_{m}}$ is the weight coefficient taking into account the "weight" (significance) in the total amount of harmful substances in the exhaust gases; $T Y_{B \%}$ is the value of reducing the emission of solid particles at a certain percentage of ethyl esters in the fuel; $m_{T Y}$ is the weight coefficient taking into account the "weight" (significance) of solid particles in the total amount of harmful substances in the exhaust gases; $N O_{x_{B} \%}$ is the magnitude of the increase in emissions at a certain percentage of ethyl esters in the fuel; $m_{N O_{x}}$ is the weight coefficient taking into account the "weight" (significance) in the total amount of harmful substances in the exhaust gases.

Based on the array of experimental data we obtained when testing a diesel engine on a bench using the least squares method, the following weights were obtained $m_{C O}=0.017 ; m_{C_{n} H_{m}}=0,0178 ; m_{T Y}=0.0535 ; m_{N O_{x}}=$ 0.63 .

Using the calculated values of the exponent, formula (4) and substituting it into expression (3) by modeling, we obtain the dependencies of the total emissions of harmful substances into the atmosphere when the diesel D-243 is operating on various mixed fuels containing ethyl esters. Dependencies are shown in Fig. 3.

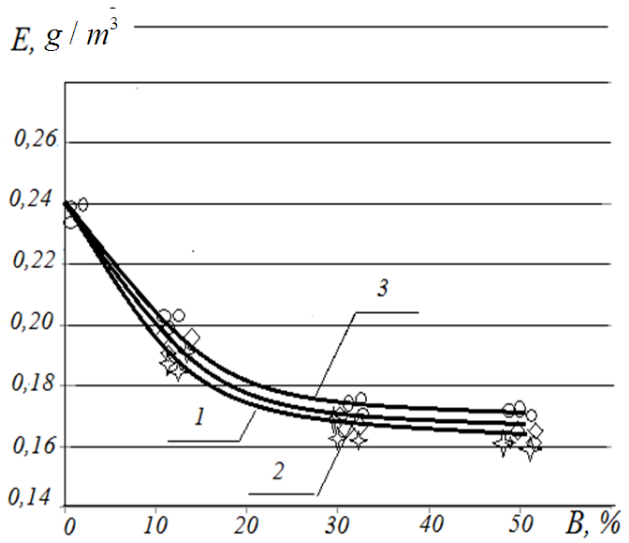

Fig. 3. Dependence on the change in the total emission of harmful substances: 1 . ethyl esters of rapeseed oil; 2. ethyl esters of sunflower oil; 3 . ethyl esters of soybean oil.

The analysis of the presented dependences allows to conclude that the intensive reduction of emissions of 
harmful substances into the atmosphere is typical for composite fuels $B 10-B 30$. Further increase in ethyl esters in diesel fuel does not create a greater effect. In our opinion, this is due to the contradiction of a simultaneous decrease $C O, C_{n} H_{m}, T Y$ and increase $N O_{x}$. Due to the fact that the weighting factor of the indicator is $N O_{x}$ quite high, there is a loss of the effect of the total reduction in the emission of harmful substances $E$, dimensionality $\mathrm{g} / \mathrm{m}^{3}$.

Further studies of the kinematic viscosity of the mixture of fuel compositions, the results of which are presented in Fig. 4. in the form of viscosity-temperature characteristics.

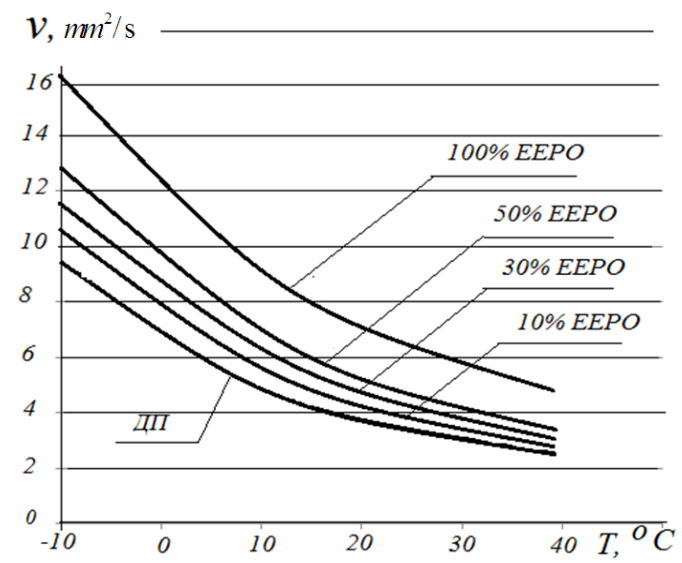

Fig. 4. Viscosity-temperature characteristics of diesel fuel in various volumetric concentrations of ethyl esters of rapeseed oil

These dependences are theoretical, since they were obtained by modeling using formulas (5) and (6) and the ASTM method D7152-11 and are intended to take into account the viscosity factor of mixed fuels when choosing the optimal volumetric concentrations of ethyl esters in diesel fuel for winter and summer periods of operation:

$$
\begin{aligned}
v_{E E P O} & =12,65 \exp (-0,0245 \cdot T), \mathrm{mm}^{2} / \mathrm{s} \\
v_{D F} & =7,2 \cdot \exp (-0,028 \cdot T), \mathrm{mm}^{2} / \mathrm{s}
\end{aligned}
$$

where $v_{E E P O}, v_{D F}$ is the kinematic viscosity of ethyl esters of rapeseed oil and diesel fuel, $\mathrm{mm}^{2} / \mathrm{s} ; T$ is fuel temperature, ${ }^{\circ} \mathrm{C}$.

Conducted studies allow us to determine the optimal ratio of the mixed composition, taking into account the technical and operational characteristics. For this purpose, in accordance with the second theorem of similarity and simulation ( $\pi$-theorem), a complex optimization criterion is obtained $K_{o p t}$ :

$$
K_{o p t}=M_{k p} \cdot G_{V}^{-1} \cdot E^{-1} \cdot v_{E E}^{-1}=\frac{M_{k p}}{G_{V} \cdot E \cdot v_{E E}}
$$

where $M_{k p}$ is the torque on the shaft of the diesel engine; $G_{V}$ is volumetric fuel consumption of diesel, $\mathrm{m}^{3} / \mathrm{s} ; E$ is the amount of harmful substances emitted into the atmosphere, Fig. 5; $v_{E E}$ is kinematic fuel viscosity, $\mathrm{m}^{2} / \mathrm{s}$.

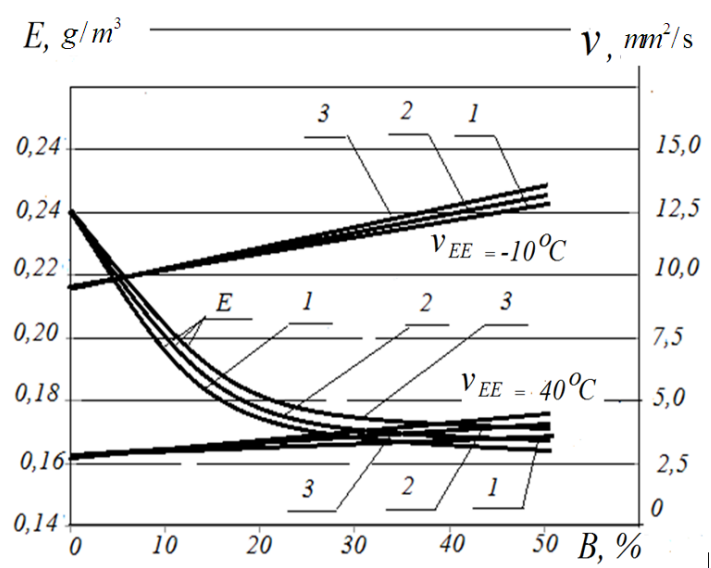

Fig. 5. Dependence on the change in the total emission of harmful substances and kinematic viscosity on the content of ethyl esters in diesel fuel:

1 - EEPO (ethyl esters of rapeseed oil);

2 - EECO (ethyl ethers of sunflower oil);

3 - EECoO (ethyl esters of soybean oil).

The criterion takes into account the volumetric fuel consumption of a diesel engine, the amount of harmful substances emitted into the atmosphere, the kinematic viscosity of the mixed fuel and the engine torque (Fig. 6)

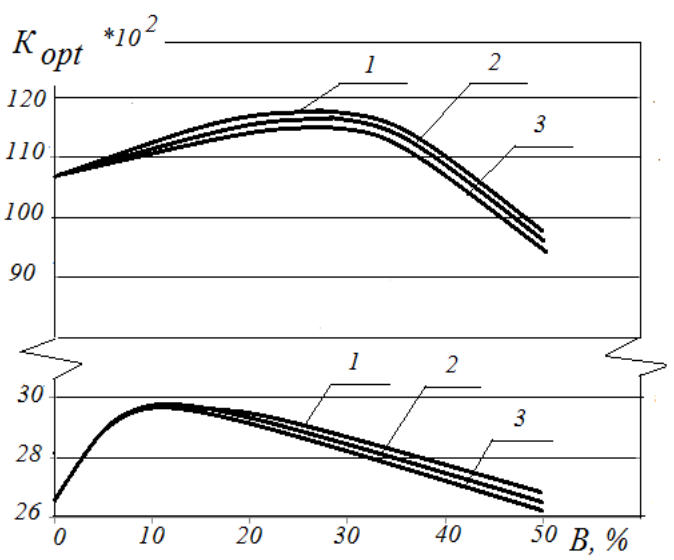

Fig. 6. Dependencies of the change in optimization criterion on the content of ethyl esters in diesel fuel:

1 - EEPO (ethyl esters of rapeseed oil);

2 - EECO (ethyl ethers of sunflower oil);

3 - EECoO (ethyl esters of soybean oil).

Analyzing the dependencies presented in Fig. 6, it can be stated: for the summer period of operation, it is necessary to use mixed fuels of not more than $30 \%$ of ethyl esters of vegetable oils; for the winter period of operation, the optimum value of the mixture composition of the fuel should contain no more than $10 \%$ of ethyl esters of vegetable oils.

To confirm the calculated data, experimental studies have been carried out to determine the fuel efficiency of the ZIL-5301 vehicle using optimal fuel mixes using main and city driving cycles, State Standard 20306-90.

From research it follows that during the operation of a vehicle on main roads with asphalt covering in the 
summer period of operation for mixed fuels containing $30 \%$ ethyl ethers, the fuel consumption increases compared to diesel fuel by $7.05 \ldots 8.67 \%$. Smaller value refers to EEPO, and more to EECoO. For the winter period of operation, when mixed fuels contain $10 \%$ ethyl esters, fuel consumption increases by $3.31 \ldots 4.34 \%$.

It is proved that during the operation of a car on the urban cycle in the summer period of operation on composite fuels containing $30 \%$ ethyl esters, fuel consumption increases by $7.1 \ldots 8.69 \%$ depending on the type of fuel. For the winter period of operation, when it is recommended to use no more than $10 \%$ of ethyl esters in diesel fuel, the consumption increases by $3.6 \ldots$ $4.22 \%$.

According to the operational data, the dependences of the average fuel consumption of a vehicle on the mass of the cargo and the type of composite fuel for the winter and summer operating periods, which are approximated by the general regression equation, are obtained:

$$
Q_{c p}=a+9,35 \cdot 10^{-4} \cdot m, l / 100 \mathrm{~km}
$$

where $a$ is dimensionless coefficient depending on the type of fuel, period and operating conditions; $m$ is weight of cargo, $\mathrm{kg}$.

The use of the regression equation (8) allows us to make a forecast on the fuel consumption of the ZIL-5301 depending on various operating conditions. This calculation mechanism will allow planning and normalizing fuel consumption in automotive enterprises when using mixed fuels based on ethyl esters of vegetable oils.

An important factor affecting the feasibility of the use of biodiesel fuel in the operation of means of transport is the economic effect that is possible as a result of its use.

Carrying out the calculation of economic efficiency it is necessary to take into account two main components: the cost of production of 1 ton of fuel, which depends on the yield of the raw element (rapeseed, sunflower, soybean) and production technologies; reduction of anthropogenic impact on the environment by reducing the emission of harmful substances into the atmosphere together with the exhaust gases.

The impact of harmful substances can be estimated by the amount of damage in UAH, which must be spent on the restoration of the environment. Such a calculation is performed according to the methodology [11].

Analysis of the results of calculations of the cost of obtaining ethyl esters from various raw materials [12] shows that with an average yield, the cost of production of ethyl esters, especially from rapeseed and sunflower, is competitive compared to diesel fuel and can be used to expand the fuel base of vehicles. At the same time there is a reserve for reducing the cost of ethyl ethers, which is associated with an increase in the yield of the above crops. As a result, the use of ethyl esters of rapeseed oil as a promising fuel for vehicles, is economically feasible.

We performed an analysis of reducing the technogenic load on the environment due to the release of harmful substances into the atmosphere when using mixed fuel $(90 \% \mathrm{DF}+10 \% \mathrm{EEPO})$ and $(70 \% \mathrm{DF}+30 \%$ EEPO) in comparison with diesel fuel.

We performed an analysis for one Zil-5301 with a D245 diesel engine and annual mileage of 64 thousand kilometers (2,000 hours of service).

According to the method, the amount of loss is calculated by the formula:

$$
3=\sum_{i=1}^{n} m_{i} \cdot 1,1 \cdot \Pi \cdot A_{i} \cdot k_{m} \cdot k_{3}
$$

where 3 is the amount of damage in UAH; $\sum_{i=1}^{n} m_{i}$ is total mass of pollutants emitted into the atmosphere, $t$; $\Pi$ is the size of the minimum wage at the time of emission of harmful substances into the atmosphere, $\mathrm{UAH} ; A_{i}$ is the dimensionless indicator of the relative hazard of the pollutant; $k_{m}$ is the coefficient that takes into account the type of settlement; $k_{3}$ is the coefficient that takes into account air pollution in the locality.

The total mass of pollutants emitted into the atmosphere for the entire period of operation (1 year) is calculated by the formula:

$$
\sum_{i=1}^{n} m_{i}=\frac{1}{1000} \cdot\left(\sum_{i=1}^{n} G_{\theta}+\sum_{i=1}^{n} G_{m}\right) \cdot T
$$

where $n$ is the number of engines, in this case, the calculation is carried out on a single engine; $\sum_{i=1}^{n} G_{\theta}$ is the total mass of air emitted into the atmosphere by the engine in one hour of operation, $\mathrm{kg} / \mathrm{h} ; \sum_{i=1}^{n} G_{m}$ is hourly fuel consumption, $\mathrm{kg} / \mathrm{h} ; T$ is engine running time, $\mathrm{h}$.

The total air mass emitted by diesel in one hour of operation:

$$
G_{\theta}=30 \cdot i \cdot V \cdot n \cdot \rho, \mathrm{kg} / \mathrm{h}
$$

where $i$ is the number of cylinders for D-245; $V$ is volume cylinder, $m^{3}$. For D-245 $V=1,18 \cdot 10^{-3}, m^{3} ; n$ rated speed, rpm. for D-245 $n=2400 \mathrm{rpm} ; \rho$ - air density, $\mathrm{kg} / \mathrm{m}^{3} . \rho=1 \mathrm{~kg} / \mathrm{m}^{3}$.

The total mass of fuel for one hour of engine operation, that is, the hourly fuel consumption is determined by the formula:

$$
G_{m}=\frac{g_{e} \cdot N_{e}}{1000}, \mathrm{~kg} / \mathrm{h}
$$

where $g_{e}$ is specific effective fuel consumption, $\mathrm{g} / \mathrm{kW} \cdot \mathrm{h}$. For D-245 $g_{e}=245 \mathrm{~g} / \mathrm{kW} \cdot \mathrm{h} ; N_{e}$ - diesel rated power, $\mathrm{kW}$. For diesel engine D-245 $N_{e}=73 \mathrm{~kW}$.

To calculate the amount of losses caused to the environment by emissions of harmful substances by a 
diesel engine according to the formula (9), it is necessary to determine the following initial data.

1. The minimum wage as of $01 / 01 / 2018$ in Ukraine is 3200 UAH.

2. A dimensionless relative hazard indicator of the $i^{\text {th }}$ pollutant during operation on a diesel engine $\mathrm{A}_{\mathrm{DF}}=1$. When operating on mixed fuels, this figure will change. According to the measurements made in the third section of this work, the composition of the exhaust gases changes: the opacity of the exhaust gases decreases by $6.76-10.6 \%$; carbon dioxide emissions are reduced by $8.4-18.94 \%$; unburned hydrocarbons are reduced by 12 $21.74 \%$; nitrogen oxide emissions increase by 1.0 $1.46 \%$.

Taking into account formula, we calculated the average value of the reduction of harmful substances in exhaust gases during operation at $(90 \% \mathrm{DF}+10 \%$ EEPO):

$A_{c p}=1-Q_{10 \%}=1-0,172=0,828, \quad$ consequently, $A_{c p}=0,828$.

When operating on $(70 \% \mathrm{DF}+30 \%$ EEPO):

$A_{c p}=1-Q_{30 \%}=1-0,354=0,646$, consequently, $A_{c p}=0,646$.

3 . The coefficient $k_{m}$ that takes into account the type of settlement is determined from the annex to the methodology, $k_{m}=2,25$.

4. The coefficient that takes into account air pollution, according to the recommendations, we assume equal to 1 .

The economic effect of the use of composite fuels is calculated as the difference between the size of the losses inflicted on the environment during the operation of one car during the year on the DF and $(90 \% \mathrm{DF}+$ $10 \%$ EEPO):

$$
\begin{aligned}
& \Delta 3=3_{D F}-3_{90 \% D F+10 \% E E P O}=5692856-4713324= \\
& =979572 U A H \\
& \text { on the DF and }(70 \% \mathrm{DF}+30 \% \mathrm{EEPO}): \\
& \Delta 3=3_{D F}-3_{70 \% D F+30 \% E E P O}=5692896-3677303= \\
& =2015593 U A H
\end{aligned}
$$

\section{Findings}

The concusions of our study are the following:

1. The source analysis showes that the operation vehicles on diesel oils based on veget methyl esters of vegetable oils and their mixtures makes possible a reduction in the smoke of exhaust gases and the content of products of incomplete combustion of fuel, which leads to a reduction of the environmental pollution. The physicochemical properties of vegetable oils and their fuels influence parameters of the fuel supply process and consequently change the characteristics of the injection and spraying of these fuels, the processes of blending and combustion, filtration through fuel filters of fine purification. High density and kinematic viscosity cause an increase in their cycle feed rate and hourly consumption of biodiesel compared to diesel. The source analysis figured out that methyl esters reduce the reliability of fuel system elements due to the negative impact of residual methanol on the sealing materials and filter elements, which requires the development of scientifically sound guidelines for the operation of biodiesel vehicles and biodiesel vehicles.

2. A structural analysis of the reliability of the fuel system of diesel vehicles was made by using the basic principles of the operations theory. Mathematical expressions were obtained to determine the probability of failure of fuel system operation and the probability of failure of its elements when operating on different types of fuel. The calculations were made to expose failures and restoration of working condition, the probability of failure of each element of the fuel system and the probability of failure of the fuel system as a whole on different types of fuel by using the developed mathematical apparatus and statistics. Dependencies obtained determine the degree of influence of different types of biofuels and its volume fraction in oil diesel on the reliability of the fuel system. The results of the simulation of the probability of failure-free operation of the fuel system and the coefficient of technical use suggest that the use of blended fuels EERO content can be increased to $30 \%$, while the content of methyl esters in the mixed composition should not exceed $10 \%$.

3. The dependence of the effective power and the specific fuel consumption applying mixed fuels based on ethyl esters of rapeseed, sunflower and soybean oils was obtained experimentally. The paper shows that the use of rapeseed oil ethyl esters reduces the effective power up to $9 \%$, the sunflower oil ethyl esters up to $11 \%$, the soybean oil ethyl esters up to $13 \%$, while increasing the specific fuel consumption by $10 \%, 12 \%$ and $14 \%$ respectively. Dependences of reduction of emissions of harmful substances into the atmosphere in the exhaust gases were obtained by using different types of mixed fuels. It has been established that the use of ethyl esters reduces the emission by $37 \ldots 40 \%$, the emission by $27 \ldots$ $29 \%$, the emission of particulate matter (soot) by $16 \ldots$ $20 \%$ while increasing the emission by $5.4 \ldots 7.4 \%$. The simulation obtained the dependence of the change in the total emission of harmful substances in the units of the exhaust gas volume for different mixtures of mixed fuels. It is calculated that the maximum effect achieve fuels containing $10 \ldots 30 \%$ of ethyl esters. A further increase in the percentage of ethyl esters in diesel does not have the effect of increasing the content of the exhaust gases.

4.The dimensionless criterion of optimization of the mixed composition of biofuels for operation of means of transport is obtained based on the theory of similarity and the method of dimensions. The criterion takes into account the volumetric fuel consumption by diesel, the amount of harmful substances emitted into the atmosphere, the kinematic viscosity of the mixed fuel and the torque on the crankshaft of the engine. The optimum content of ethyl esters of various oils in diesel fuel is established, which for the summer period of operation does not exceed $30 \%$ of ethyl esters, and for winter operation no more than $10 \%$.

5. The fuel economy of the ZIL 5301 was evaluated when operating at the optimal mixed fuel depots according to the main and city driving cycles. It is 
established that during the operation of the car on asphalt-paved main roads in the summer on mixed fuel containing $30 \%$ of ethyl esters, the fuel consumption increases in comparison with diesel fuel by $7.05 \ldots$ $8.67 \%$. Less importance relates to EERO and more to EESO. For winter operation, when the blended fuel contains up to $10 \%$ of ethyl esters, the fuel consumption increases by $3.31 \ldots 4.34 \%$. The dependence of the average fuel consumption by the car on the mass of the transported cargo and the type of mixed fuels for winter and summer operating periods, which are approximated by the general regression equation, were obtained. The equation makes it possible to predict the fuel consumption of a car when using blended fuels based on ethyl esters, as well as to develop normative indicators for the blended fuel consumption for the winter and summer operating periods, which is of practical importance for this work.

6. The evaluation shows economic efficiency of using ethyl esters of vegetable oils as fuel for vehicles. A reduction of damage caused to the environment by the release of harmful substances into the atmosphere by using a mixture of ethyl esters of rapeseed oil in comparison with the losses caused by the use of mineral diesel fuel has been carried out. The economic effect of reducing man-made environmental impact in the operation of one car with an annual mileage of 64 thousand kilometers on B10 fuel $(90 \%$ DP $+10 \%$ EERO) will be UAH 979 572, on B30 fuel (70\% DP + $30 \%$ EERO) economic the effect is equal to 2015593 $\mathrm{UAH}$.

\section{REFERENCES}

1. The data of the State Statistics Committee of Ukraine, URL: www.ukrstat.gov.ua.

2. D.Muzylyov, A.Kravcov, N.Karnayh, N.Berezhnaja and O.Kutiya, Development of a methodology for choosing conditions of interaction between harvesting and transport complexes, Eastern European Journal of Enterprise Technologies, 2 (3) (2016).

3. T. V. Dikun, P. I. Polyans'kij, Analysis of the effectiveness of using biodiesel in internal combustion engines. Oil and gas, Oil and gas energy, 1, 86-93 (2015).
4. S. Chernenko, A. Atamas', Economic and energy performance of the engine when using biofuel from rapeseed, Bulletin of the Kremenchug State Polytechnic University named after Nikolai Ostrogradsky, 2, 85-89 (2007).

5. V. A. Vojtov, M. V. Karnauh, O. B. Kalyuzhnij, M. S. Dacenko, Studies of the features of biodiesel filtration through paper filters of fine cleaning of diesel engines, Design, production and operation of agricultural machinery. 40 (1), 282-286 (2010).

6. A. M. Levterov, V. D. Savic'kij, N. Yu. Gladkova, Development of methods for adapting diesel engines to bio-petroleum fuel compositions, Mechanical Engineering Issues, 3, 54-63 (2017).

7. Linus N. Okoro, Fadila I. Sambo, Lawal Mukhtar, Clifford Nwaeburu, Thermodynamic and Viscometric Evaluation of Biodiesel and Blends from Olive Oil and Cashew Nut Oil, Research Journal of Chemical Sciences, 1(4), 90-97 (2011).

8. J. S. Eloka-Eboka, A. C. Ibrahim, Engine performance test of bio-diesel produced from african mesquite seed oil using pyrolysis. African Journal of Physics, 3, 241 -254 (2010).

9. M. V. Karnaukh, Expanding the fuel base of automobile transport by using ethyl esters of fatty acids of vegetable oils, Bulletin of the Kharkov National Automobile and Highway University, 49, 47-51 (2010).

10. The method of producing biodiesel in the form of ethyl esters of oils and fats: pat. 65058 Ukraine: MPK S10L 1/19 (2006/1). №U201105331; zayavl. 26.04.2011; publ. 25.11.2011, bulletin, 22. 4 (2011).

11. Methodology for calculating the amount of compensation for losses caused as a result of regulatory emissions of pollutants into the atmosphere, Ministry of Jusice of Ukraine, Jan. $21^{\text {th }}$ 2009, 48 (2009).

12. V.A.Voytov, M. V. Karnaukh, M.S. Datsenko, Estimation of the cost of manufacturing ethyl esters of vegetable fatty, Bulletin of the Kharkov National University of Agriculture named after Peter Vasilenko, 108, 105-115 (2010). 